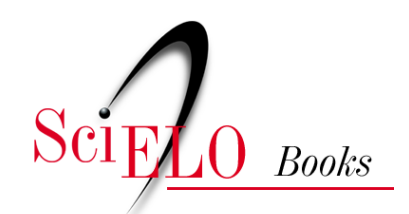

\title{
A flutuação turística na região das Baixadas Litorâneas (RJ) uma análise centrada nos municípios de Armação dos Búzios, Arraial do Cabo e Cabo Frio
}

\author{
Ulisses Fernandes
}

\section{SciELO Books / SciELO Livros / SciELO Libros}

FERNANDES, U. A flutuação turística na região das Baixadas Litorâneas (RJ): uma análise centrada nos municípios de Armação dos Búzios, Arraial do Cabo e Cabo Frio In: MARAFON, G.J., and RIBEIRO, M.A. orgs. Revisitando o território fluminense, VI [online]. Rio de Janeiro: EDUERJ, 2017, pp. 259-274. ISBN: 978-85-7511-457-5. https://doi.org/10.7476/9788575114575.0013.

All the contents of this work, except where otherwise noted, is licensed under a $\underline{\text { Creative Commons Attribution } 4.0}$ International license.

Todo o conteúdo deste trabalho, exceto quando houver ressalva, é publicado sob a licença Creative Commons Atribição $\underline{4.0}$.

Todo el contenido de esta obra, excepto donde se indique lo contrario, está bajo licencia de la licencia $\underline{\text { Creative Commons }}$ $\underline{\text { Reconocimento 4.0. }}$. 


\section{A flutuação turística na região das Baixadas Litorâneas (RJ): uma análise centrada nos municípios de Armação dos Búzios, Arraial do Cabo e Cabo Frio'}

Ulisses Fernandes ${ }^{2}$

\section{Introdução}

0

artigo ora apresentado advém de relatório de pesquisa realizado para atender a apoio institucional a recém-doutores da Fundação Carlos Chagas de Amparo à Pesquisa - RJ (Faperj). Sua motivação básica, para além do vínculo com a realidade socioespacial fluminense, está na possibilidade de se manter vínculo com uma das temáticas de maior apelo social dos últimos tempos: a atividade turística contemporânea.

Parte-se da tentativa de entender a abrangência do fenômeno do turismo em uma das porções do território fluminense cuja atividade turística tem despontado como uma das de maior transformação da realidade socioespacial local: a Região das Baixadas Litorâneas. A prática turística, intensificada a partir dos anos 1970, principalmente após a construção da rodovia federal BR-101 e da chamada ponte Rio-Niterói, gerou uma pretensa região turística de forte mobilidade, mesmo em nível internacional, com grande flutuação da mobilidade turística entre os municípios da supracitada região.

${ }^{1}$ Este trabalho resulta de pesquisa com o apoio institucional da Fundação Carlos Chagas de Amparo à Pesquisa - RJ (Faperj).

2 Docente Adjunto do Instituto de Geografia da UERJ; Programa de Pós-Graduação em Geografia da UERJ 
Por entendimento prévio, a pesquisa arbitrou duas porções específicas dentro da região indicada: uma relacionada aos municípios onde, tradicionalmente, há maior presença de turistas de outras unidades federativas do Brasil e até mesmo de outros países, sendo abrangida pelos municípios de Armação dos Búzios, Arraial do Cabo e Cabo Frio; a outra é composta pelos municípios restantes, onde esse fluxo de turistas "externos" é bem menor e, muitas vezes, os veranistas se apresentam em número muito grande.

Neste artigo, trata-se especificamente da primeira porção territorial destacada. Assim, demonstra-se a ocorrência de uma flutuação atrelada à mobilidade turística dentro da porção do território fluminense cujo senso comum reconhece como Regiāo dos Lagos. Daí deriva o principal questionamento a ser feito: se, de fato, há uma interação regional notabilizada pela atividade turística, capaz de estabelecer laços entre os municípios locais quanto à questão da flutuação-mobilidade turística. Por outro lado, como questão secundária, torna-se fundamental definir se há adequação conceitual para tratar o recorte eleito como uma região turística.

Este estudo baseou-se em revisão bibliográfica e pesquisa de campo, com a aplicação de duzentos questionários. Para além do trato quantitativo, também foi feita uma abordagem qualitativa na forma de entrevistas. A redação final, na forma de artigo, pressupõe a análise teórico-conceitual inicial, bem como posterior interação com o recorte empírico, principalmente pela utilização das entrevistas e dos dados coletados em campo.

\section{Turismo: motivações e mobilidade}

O turismo é, decididamente, um fenômeno que passa pela esfera econômica, social, política e cultural, apresentando-se de modo significativo nas "sociedades ditas pós-industriais" (Rodrigues, 1999, p. 17). Desse modo, vem ganhando cada vez mais espaço tanto nas discussões políticas e acadêmicas quanto nas populares. No entanto, há autores que advogam a necessidade de um estudo científico do turismo mais apurado, como nos contam Gareth Shaw e Allan Williams, pois, "embora venha crescendo o número de exceçôes, o estudo científico do turismo ainda é frequentemente descritivo, ateórico e caoticamente conceitualizado, por ser extraído das relações sociais mais amplas" (Shaw e William, 2004, p. 1).

Pensar o turismo implica, entre outras coisas, debater a mobilidade que ocorre durante o fenômeno. É necessário, contudo, atentar para o fato de que a mobilidade turística está interligada a várias formas de mobilidade, "tais como a migração de trabalho ou conhecimento e transferência de capital" (idem, ibidem). A mobilidade de pessoas, no âmbito internacional, foi efetivamente afetada com a globalização. O fluxo turístico, em determinados espaços e lugares, é moldado pelo processo de globalização, requerendo entendimento do turismo como um fenômeno que está estritamente ligado ao cotidiano, à constituição de comunidades e ao funcionamento do sistema social e natural, e não como um fenômeno social independente.

Nosso desafio, na qualidade de pesquisadores do turismo, é buscar entender como o turismo molda e é moldado pelos processos sociais. Para tanto, faz-se necessária uma perspectiva de mudança e, nesse sentido, baseamo-nos no conceito de vias e fluxos, entendido como "rede de máquinas, tecnologia, organizações, textos e atores que constituem vários nós interconectados, ao longo do qual o fluxo pode ser retransmitido" (Urry, 2000, p. 35). Urry, em verdade, propõe uma paisagem do turismo que seria composta por vias e fluxos. Segundo ele, o espaço do turismo é fortemente estruturado por vias - autoestradas, rotas de voo, aeroportos - que facilitam e canalizam o movimento. Assim, 


\section{A flutuação turística na região das Baixadas Litorâneas (RJ)}

as vias mais distorcem do que afirmam ou reforçam as fronteiras, é verdade que muitas viagens ocorrem fora destas, mas são fundamentais para entender o volume dos fluxos do turismo [...]. Essas vias são mais do que apenas rotas de transporte, estas são também compostas pelos investimentos materiais em hotéis, restaurantes e outros serviços que facilitam a viagem (Urry apud Shaw e Williams, 2004, p. 3).

O turismo de massa - que, atualmente, encontramos no Brasil, em cidades como Salvador (BA) durante o carnaval e em Cabo Frio (RJ) na alta temporada do verão, quando os turistas, em geral da classe média, dirigem-se a essas localidades para usufruir de um turismo sazonal e de mais baixo custo, em comparação ao turismo elitista - é particularmente influenciado por essa estrutura constituída por vias que, destarte, vão facilitar o fluxo turístico. Mas não só esse tipo de turismo é constituído por vias e fluxos; existem outros também, como o ecoturismo e o turismo esportivo.

A importância das vias, pois, reside no fato de contribuírem para a predominância da localização relativa sobre a localização absoluta. $\mathrm{Na}$ dita pós-modernidade, a distância direta entre o ponto de origem e o ponto de destino perde importância, caracterizando, lato sensu, o modo de vida do homem moderno, que, no contexto na globalização do turismo, interconecta-se com o mundo de modo ágil e efêmero, o que incide, muitas vezes, na própria flutuação turística. As vias se caracterizam pela inércia, resultando da tecnologia, do capital investido e do conhecimento embutido nelas. No entanto, podem sofrer mudanças que variam de acordo com os interesses do capital. Por isso, as vias estão em constante mutação, sendo (re)construídas e revistas no espaço da globalização do turismo.

Como já assinalado, o turismo de massa é constituído por vias e fluxos que permitem maior mobilidade dos turistas no espaço. No entanto, cabe indagar: a existência dessas vias e fluxos funcionaria também como motivação turística? E essa pretensa facilidade de mobilidade justificaria a flutuação turística, ou seja, o ir e vir entre localidades distintas dentro de uma mesma área? E, se assim funcionarem, são hermeticamente a única motivação para que uma pessoa se desloque? De fato, as vias e os fluxos se encaixam na categoria de motivação turística, mas não estão isoladas; pelo contrário, há muitas outras motivações que, neste artigo, serão englobadas em categorias gerais, apenas para fins didáticos.

Em primeiro lugar, é preciso clarificar o que se entende por motivação. O conceito de motivação sugere que os indivíduos constantemente visam alcançar um estado de estabilidade (Gossens apud Shaw e Williams, 2004). Além disso, "tal equilíbrio é interrompido quando o individuo percebe que necessita de algo. Isso levou à criação das necessidades básicas na experiência dos turistas, tais como: novidades, satisfação sexual, estimulação, relaxamento e a autoexpressão" (Shaw e Williams, 2004, p. 140).

Em segundo lugar, as abordagens concernentes à motivação do turismo apontam para similaridades que emergiram de diferentes autores. Nesse caso, comungamos da mesma metodologia empregada pelos autores supracitados, que defendem que "essas diferentes abordagens podem ser categorizadas em três perspectivas; reducionista, estruturalista e funcionalista” (Shaw e Williams, 2004, p. 140). Deve ficar claro, pois, que essas três perspectivas propostas pelos autores não são as únicas que tentam generalizar as categorias de motivação turística, mas aquelas que sistematizam as abordagens dessa temática de modo mais abrangente.

A perspectiva reducionista, segundo Cohen (apud Shaw e Williams, 2004), entende a motivação do turismo como uma tensão entre a busca por novas experiências e a exigência de algum grau de familiaridade. O turista, de acordo com essa visão, teria como principal motivação a busca por novidades e pela identificação com o lugar. 
A perspectiva estruturalista, por sua vez, concentra-se em identificar uma série de variáveis motivacionais que seriam determinadas por fatores de repulsão e atração. Nos trabalhos que se baseiam nessa perspectiva, dá-se mais ênfase ao fator repulsão, porque seria o condicionante para a decisão do turista de viajar. Nesse sentido, observa-se "motivos mais duradouros, problemas internos ou fatores de repulsão que resultam na vontade do turista de procurar por objetos, eventos e situaçôes" (Gnoth apud Shaw e Williams, 2004, p. 141). Gossens (apud Shaw e Williams, 2004) argumenta que o conceito de emoção é o fator psicológico que conecta os fatores de atração-repulsão da motivação. Nesse sentido, "os turistas são expulsos pelas suas necessidades emocionais e atraídos pelos benefícios emocionais do local de destino" (p. 141). Motivação, para Gossens, tem relação com o consumo hedônico, em que o processo se daria em três estágios: o primeiro seria a fase do envolvimento do turista com o espaço, podendo levar a dois caminhos, a excitação e a consequente atração ou o estresse e a consequente repulsão; o segundo seria o momento em que, após o sentimento inicial, o turista processa as informações; e o terceiro seria o chamado estágio hedônico, que leva ao próprio consumo.

A terceira grande abordagem das motivações turísticas compreende o funcionalismo, proposta por Fodness (1994), que argumenta que tomamos certas atitudes em virtude de necessidades psicológicas importantes. Na perspectiva funcionalista, essas necessidades podem criar certas tensões de natureza psicológica ou física. Tais tensões, como dizem Shaw e Williams (2004), são liberadas por ações que, às vezes, envolvem sair de férias.

Dessas três abordagens, emergem dois problemas-chave: o primeiro seria o fato de essas abordagens não constituírem modelo para uma teoria sólida da motivação turística, tal como defendem Pearce e Butler (1994); o segundo está relacionado à profunda dificuldade em sistematizar as motivaçóes do turismo. No entanto, essa complexidade que reveste a sistematização das motivações turísticas não elimina a proeminente importância das motivações no processo decisório do turista. De fato, as motivaçóes constituem ponto crucial quando se analisa o fenômeno da mobilidade de uma população dentro da lógica turística. Por outro lado, o movimento de população sobre o espaço tem-se tornado cada vez mais importante na determinação das análises socioeconômicas em função dos tipos de mobilidade que estão se configurando.

Alguns autores enfocam a questão da mobilidade como parte importante da investigação em busca de entender a sociedade contemporânea. Nesse sentido, tem-se o exemplo do turismo como forma de lazer (Guimarães, 2001), que pode, por sua vez, ser inserido na categoria mobilidade, fenômeno genérico que pressupõe várias formas de transporte, deslocamento diário entre comunidades - como aqueles relativos ao trajeto casa-trabalho e vice-versa - e outras formas de viagens, assim como suas diversas inter-relações por meio de várias formas de comunicação (Lash e Urry, 1994).

Nesse contexto, as novas condiçôes de mobilidade apontariam para a configuração de um "pós-turismo" associado à presença difusa de signos em todos os lugares (Urry, 1996). Harvey (1996), ao situar as principais tendências do capitalismo, também destaca a importância dos signos, afirmando que vivemos numa dimensão da compressão de tempo/espaço em que se consomem mais símbolos e imagens do que propriamente coisas ao assimilarmos a publicidade e a mídia, dimensões especiais nesse cenário. Para Hannam, Sheller \& Urry (2006), novos lugares e tecnologias, ao mesmo tempo que aumentam a mobilidade de algumas pessoas e lugares, também aumentam a imobilidade de outras - como, por exemplo, pessoas que buscam cruzar fronteiras -, o que envolve estruturas de poder e posição de raça, gênero, classe etc. Dessa forma, tornam-se claros os efeitos da globalização sobre a mobilidade de população, uma vez que, para algumas pessoas, praticar a mobilidade, no caso a turística, consiste em uma atividade comum, enquanto, para outras, essa prática não faz parte de sua dimensão social. 


\section{A flutuação turística na região das Baixadas Litorâneas (RJ)}

Nesse contexto, parte-se para a análise de um recorte específico, o da Região das Baixadas Litorâneas no estado do Rio de Janeiro, como forma de verificar o que até então se advogou. O recorte em si guarda interconexão com o turismo de escala global, sendo objeto de consumo turístico de frequentadores oriundos de diversas porções do planeta, para além da própria escala local-nacional de atração turística. Por outro lado, guarda dimensões do que pode ser chamado de região turística, ou área turística, onde a mobilidade relativamente fácil e a coproximidade de centros turísticos incidem numa flutuação turística dentro de seus limites.

As questôes previamente apresentadas remetem à necessidade de se compreender se essa mobilidade ocorre de forma homogênea dentro de toda a região ou área turística ou se há outras motivações que determinam um uso turístico mais heterogêneo, com segregação turística, em que o fluxo seria mais ou menos intenso conforme a prévia avaliação dos centros turísticos existentes. Para tanto, torna-se necessário categorizar regiāo ou área turística, bem como avaliar sua pretensa configuração, tomando-se por base o recorte espacial eleieto nesta pesquisa.

\section{0 turismo na região das Baixadas Litorâneas do Rio de Janeiro}

Como indica o Caderno de turismo do estado do Rio de Janeiro, a atividade turística no território fluminense "é influenciada pela enorme diversidade de paisagens e características topográficas e climáticas, além das peculiaridades culturais existentes" (Gomes, 2010, p. 50). Decerto, como também preconiza o estudo, essa atividade tornou-se fundamental para o desenvolvimento de algumas porções do estado. Em muitos municípios fluminenses, inclusive, o turismo é a atividade polarizadora do desenvolvimento social e econômico. De fato, como sustenta Miguel Angelo Ribeiro (2003), "o estado do Rio de Janeiro é uma das unidades federadas que apresenta importância para a promoção do turismo brasileiro, atividade esta que merece destaque no contexto do desenvolvimento econômico de nosso estado" (p. 80). Ribeiro também destaca que

a atividade turística não pode ser pensada sem as bases geográficas e, neste contexto, podemos distinguir três condicionantes que influenciam o desenvolvimento da atividade do turismo em território fluminense. Tais condicionantes estão intimamente relacionados. São eles: (a) o elemento físico ou natural; (b) o elemento histórico e as atividades econômicas; e (c) o papel dos transportes (p. 81).

No estudo organizado por Gomes (2010), partindo da apreciação de Ribeiro (2003) quanto à importância da base geográfica, são apontadas áreas turísticas específicas nas quais os condicionantes naturais e históricos ganham destaque: áreas de ecoturismo, de praia e ecoturismo, de praia e rural, de praia, de serra e mar, de serra, serrana da Mantiqueira, Baixada Fluminense, diversificada e o Vale do Café.

Nesta pesquisa, relacionando-se motivação e mobilidade nas práticas turísticas em uma porção específica do território fluminense, a das Baixadas Litorâneas, identifica-se área turística de praia como aquela em que o recorte empírico melhor se dimensiona. A área em si se notabiliza pelas práticas turísticas dimensionadas pela orla litorânea aprazível, cuja paisagem, raiz da motivação turística, é capaz de atrair um quantitativo expressivo de visitantes e o produto turístico passa a ser acessível quando a estrutura - e também a superestrutura - turística é mobilizada nesse sentido (Boullón, 2002). Para esse autor, a paisagem como elemento da apreciação 
turística é preestabelecida na relação entre um objeto estético, que é a praia, com o observador sensível, que é o turista. Define-se, portanto, a paisagem como

uma qualidade estética que os diferentes elementos de um determinado espaço físico adquirem apenas quando o homem surge como observador animado de uma atitude contemplativa dirigida a captar suas propriedades externas, seu aspecto, seu caráter e outras particularidades que permitem apreciar sua beleza ou feiúra (Boullón, 2002, p. 120).

Definindo, pois, a importância da dimensão da paisagem praiana para a caracterização de uma área turística, parte-se para o apontamento das outras atividades turísticas que podem ser correlacionadas ao turismo de praia. No caso específico do recorte espacial deste trabalho, observa-se, ainda em acordo com Gomes (2010), a existência de práticas turísticas classificadas como turismo histórico, turismo de aventura e turismo ecológico.

De fato, na praia incidem outras possibilidades de uso turístico. A orla oceânica, por exemplo, está associada à antiga colonização desse fragmento do território brasileiro, o que, atualmente, possibilita a existência de rugosidades cujo caráter histórico-cultural também mobiliza visitantes em cidades como Cabo Frio, por exemplo. Esse mesmo mar, associado à praia, explica a ocorrência das práticas de mergulho para exploração submarina, como se verifica junto ao litoral do município de Arraial do Cabo. É a praia, enfim, que possibilita a prática de esportes náuticos, como visto, de modo geral, nos municípios supracitados e também em Armação dos Búzios.

O Mapa $1^{3}$ identifica os municípios abrangidos por essa área turística. São eles: Araruama, Armação dos Búzios, Arraial do Cabo, Cabo Frio, Iguaba Grande, Maricá, Rio das Ostras, São Pedro da Aldeia e Saquarema. Como o Caderno de turismo do estado do Rio de Janeiro destaca, "seu ambiente litorâneo é o principal atrativo turístico, tanto que a região de governo que envolve esta área é conhecida como Costa do Sol” (Gomes, 2010). Observa-se que, no Plano Diretor de Turismo do Estado do Rio de Janeiro, os municípios indicados fazem parte da Região Turística da Costa do Sol, onde estão presentes, para além dos municípios já citados, Casimiro de Abreu, Macaé, Carapebus e Quissamã (Mapa 2).

A Secretaria de Turismo do Estado do Rio de Janeiro, através do Plano Diretor de Turismo do Estado do Rio de Janeiro, reconhece 12 regiōes turísticas no estado, das quais seis são consideradas estratégicas: Costa Verde, Agulhas Negras, Vale do Café, Rio de Janeiro e Niterói, Serra Verde Imperial e aquela que representa o objeto deste artigo, a Costa do Sol. Registre-se que o referido plano aponta para regiōes turísticas com características homogêneas, o que difere da proposta organizada por Gomes (2010). Em consonância com o plano diretor,

o mapeamento turístico no estado resultou na aglutinação de um determinado número de municípios, conferindo praticidade à operação conjunta de ações propostas para o desenvolvimento do setor, sem perder de vista a necessária integração das diversas regiōes na realização e promoção do produto turístico de todo o estado. As regiões turísticas foram

\footnotetext{
3 O mapa foi elaborado pelo Núcleo de Estudos de Geografia Fluminense (Negef), vinculado ao Instituto de Geografia da UERJ. O núcleo participou ativamente da elaboração do estudo organizado por Gomes (2010): o Caderno de turismo do estado do Rio de Janeiro.
} 


\section{A flutuação turística na região das Baixadas Litorâneas (RJ)}

identificadas de modo a guardarem, internamente, um sentido de homogeneidade e complementaridade traduzidas pela identidade geográfica, paisagística, territorial e da oferta de infraestrutura e serviços. ${ }^{4}$

Nesse sentido, ao propor um estudo da mobilidade turística na região das Baixadas Litorâneas, decerto haveria uma premissa, a de destacar o conceito de região. Entretanto, considerando-se a análise de uso turístico, como aponta Boullón (2002), esse não é o conceito mais adequado. Boullón entende que os atrativos turísticos presentes em determinado espaço são relativamente pouco significativos e, portanto, só excepcionalmente se tocam. Essa condição impediria a conformação de uma região turística em si:

visto que o espaço turístico é entrecortado, não se pode recorrer a técnicas de regionalização para proceder a sua delimitação porque, de acordo com elas, seria preciso abranger toda a superfície do país ou da região em estudo e, caso isso fosse feito, grandes superfícies que não são turísticas figurariam como turísticas, cometendo-se um erro. Isso significa que regiōes turísticas não existem (Boullón, 2002, p. 79).

Mapa 1. Áreas turísticas no estado do Rio de Janeiro

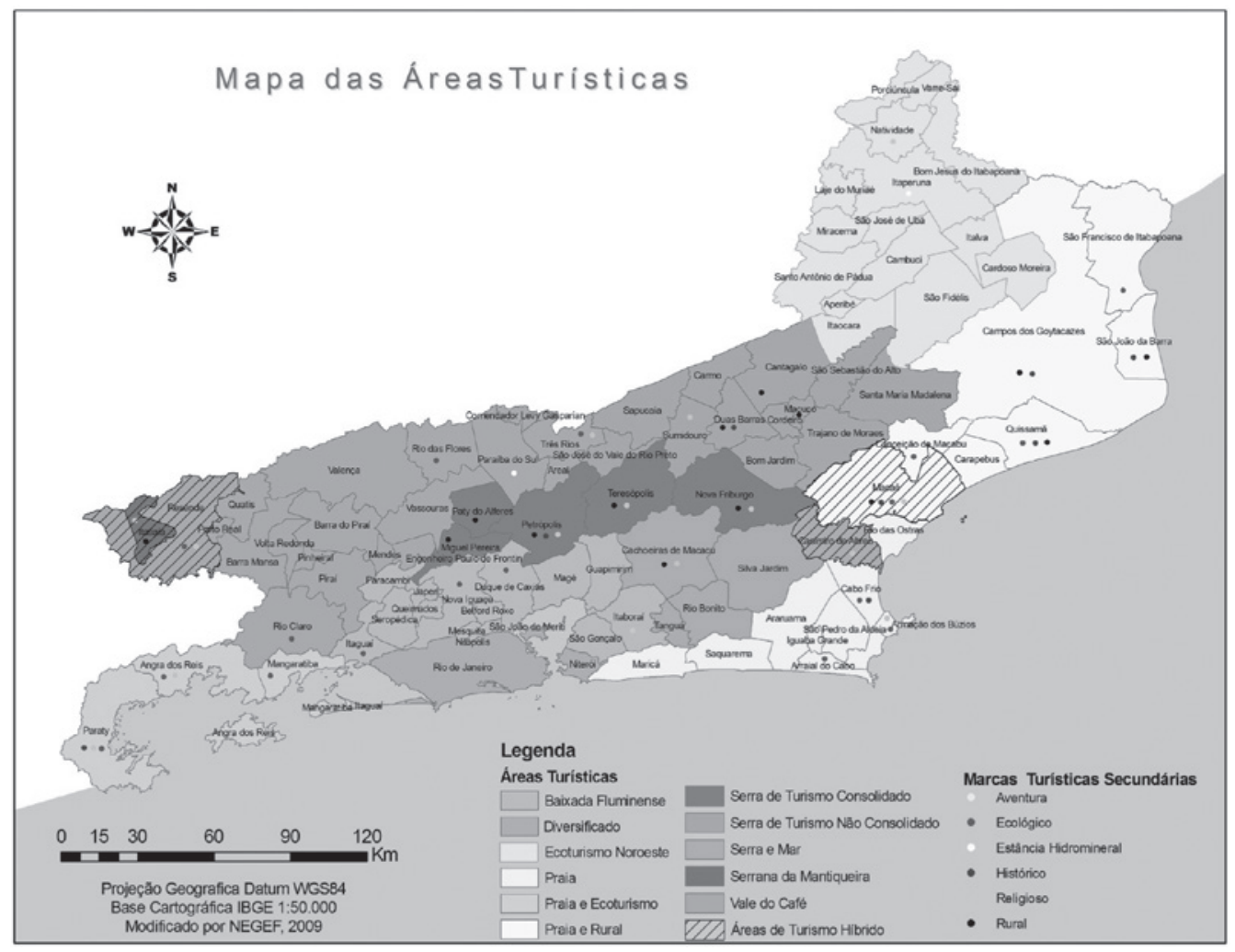

Fonte: Gomes, 2010.

${ }^{4}$ Conforme disposto no sítio eletrônico da SeTur, Secretaria de Turismo do Estado do Rio de Janeiro. Disponível em: http://www.turisrio.rj.gov.br/projetos.asp. Acesso em: 30 de maio de 2012. 
Mapa 2. As regiôes turísticas do estado do Rio de Janeiro

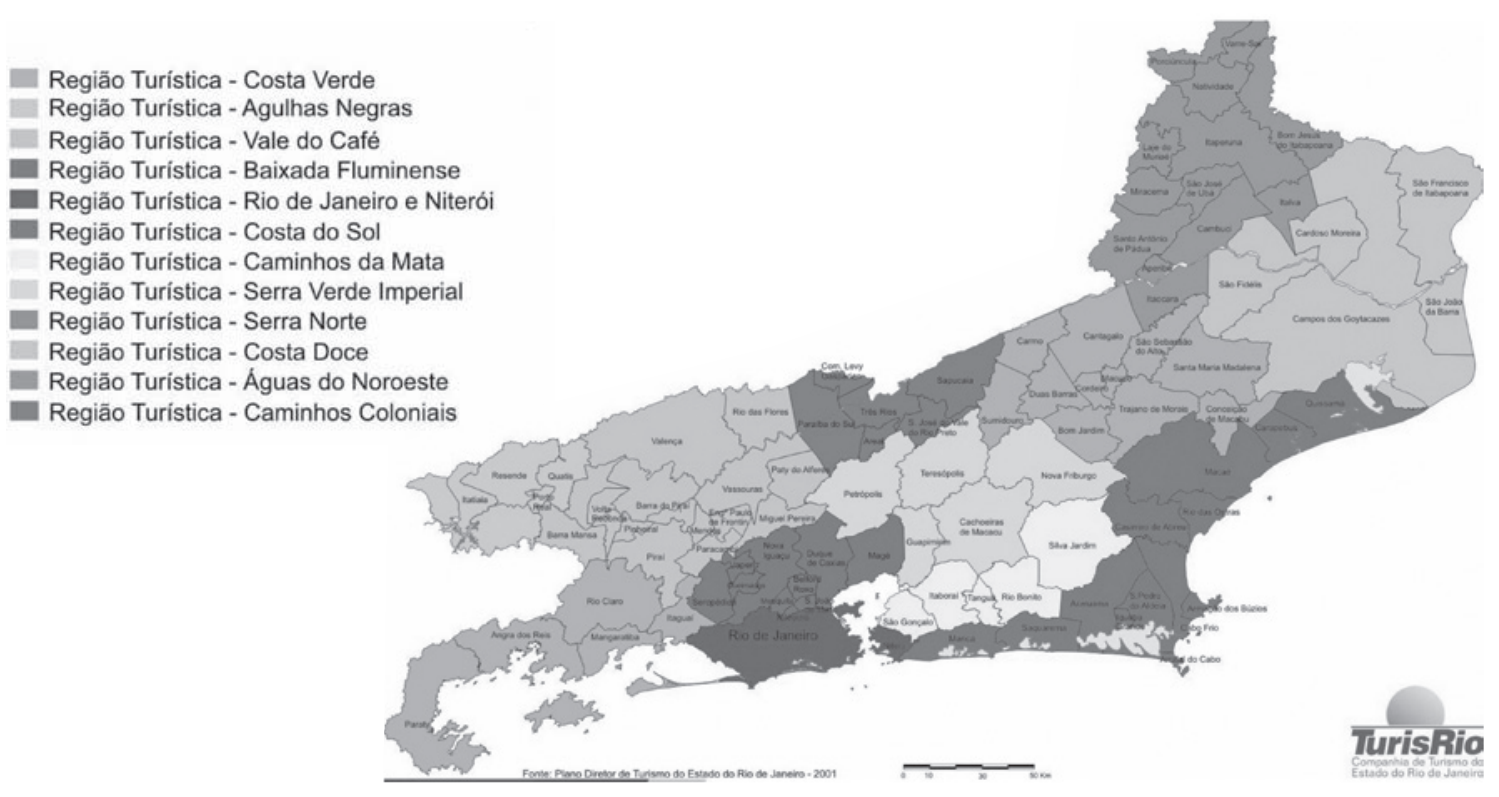

Fonte: Plano Diretor de Turismo do Estado do Rio de Janeiro. TurisRio/Companhia de Turismo do Estado do Rio de Janeiro.

Nesse contexto, a proposta de tratamento da espacialização turística fluminense estaria mais próxima daquela organizada por Gomes (2010) no Caderno de turismo do estado do Rio de Janeiro. Esse é o entendimento de Boullón (2002), que justifica o desenvolvimento da ideia de espaço turístico. A concentração de atrativos turísticos no território, segundo a lógica desse autor, indica a existência de múltiplos agrupamentos e concentrações em que é possível destacar zonas, áreas, complexos e centros turísticos. Essa proposta permite avançar no sentido de compreender, dentro da chamada regiáo das Baixadas Litorâneas, no estado do Rio de Janeiro, as atividades e o aparato turísticos concentrados em três municípios: Cabo Frio, Arraial do Cabo e Armação dos Búzios.

Na verdade, o Plano Diretor de Turismo do Estado do Rio de Janeiro atende a uma necessidade própria do Poder Público fluminense de considerar a regionalização da atividade turística. O Estado, conforme disposto por Marafon et al. (2012), como uma proposta de política pública, dimensiona o espaço fluminense em regiôes de governo. O foco da proposta, então, consiste em direcionar as ações públicas voltadas ao desenvolvimento de acordo com as especificidades geográficas, em sua visão mais abrangente, de cada região fluminense. Seria, portanto, plenamente cabível que o agente público promovesse uma leitura regional para o desenvolvimento turístico do estado. Assim, o entendimento de uma região turística, embora não desmerecido como um todo, deixa de atender aos objetivos desta pesquisa. Por um lado, a pertinência da região das Baixadas Litorâneas como indicativo de uma proposta de política pública de desenvolvimento é determinante para se estabelecer o recorte do presente estudo. Por outro, do ponto de vista teórico-conceitual, não cabe empreender uma leitura da mobilidade turística em dada porção do espaço fluminense considerando o conceito de 
região. Nesse sentido, considerando-se sobretudo as ideias de Boullón (2002), busca-se compreender a dinâmica turística presente no recorte espacial eleito.

\section{A flutuação: mobilidade turística na região das Baixadas Litorâneas (RJ)}

A flutuação-mobilidade turística está atrelada à própria significação turística de dado recorte espacial. O espaço turístico depende, portanto, para além dos próprios atrativos turísticos, do empreendimento turístico em si e da infraestrutura turística disponibilizada. A mobilidade é indicativo daquilo que Boullón (2002) chama de área turística, pois envolve a existência de dois ou mais centros turísticos, conforme observa o próprio autor, pois

as áreas turísticas devem estar dotadas de atrativos turísticos contíguos [...] e necessitam, da mesma forma, de uma infraestrutura de transporte e comunicação que possa funcionar como um subsistema, requerem a presença mínima de um centro turístico e, se sua infraestrutura e recursos de equipamentos e serviços são insuficientes, devem ser registrados como potenciais (p. 83).

O centro turístico, por sua vez, guarda especificidades dimensionadas pelo quantitativo de atrativos capazes de motivar o uso turístico de determinado espaço. Ainda segundo Boullón (2002), observa-se que o centro turístico "é todo o conglomerado urbano que conta em seu próprio território ou dentro de seu raio de influência com atrativos turísticos de tipo e hierarquia suficientes para motivar uma viagem turística" (p. 84).

Nesse sentido, dentro da região de governo das Baixadas Litorâneas, entre os municípios nela encontrados, apenas três guardam atributos suficientes para ser considerados centros turísticos: Arraial do Cabo, Cabo Frio e Armação dos Búzios. Para além do entendimento dos atributos indicados por Boullón (2002), essa assertiva deriva da própria pesquisa empírica realizada. Metodologicamente, houve uma predefinição dos três municípios para a coleta de dados quanto à mobilidade turística. Obviamente, partiu-se das orientações de Boullón (2002) quanto ao fato de que os centros turísticos necessitariam de certos atributos para ser considerados como tal, ou seja, a predefinição dos municípios eleitos não foi aleatória. No entanto, a coleta de dados mostrou que, de fato, esses três municípios guardavam a condição previamente entendida. Na verdade, o atendimento ao objetivo básico da pesquisa envolve demonstrar se há de fato uma flutuação-mobilidade turística entre os municípios da região de governo indicada. Se, por um lado, os dados apontam para uma forte mobilidade entre os três municípios em destaque, por outro, demonstram que os demais municípios da região de governo têm muito pouca interação entre si (Gráficos 2, 5 e 6). Isso, por si só, já é indicativo da análise antes feita, ou seja, de que não era possível tratar o recorte como região turística, mas tão somente como área turística. Em parte, porque os municípios que se destacam no trato turístico são apenas três e, em parte, porque o fragmento de espaço e alocação dos objetos turísticos, de infraestrutura de comunicação e dos empreendimentos encontra-se concentrado na franja litorânea da região de governo. 
Coletaram-se dados nos três municípios, com a aplicação de duzentos questionários. Para as demandas específicas desta pesquisa, destacam-se os dados relativos aos municípios visitados pelos turistas entrevistados. Elegeram-se atrativos turísticos significativos desses três centros turísticos: a Praia do Forte, em Cabo Frio; a Prainha, em Arraial do Cabo; e a Praia de Geribá, em Armação dos Búzios. Essas praias são as mais conhecidas e frequentadas pelos turistas nos respectivos municípios. A coleta, portanto, objetivava saber se seria possível identificar nesses atrativos de maior expoente turistas hospedados de outros municípios da região de governo. Também objetivava saber se os turistas ali presentes se deslocavam para as atrações turísticas de outros municípios da região.

Dos turistas entrevistados em Arraial do Cabo, apenas 2\% dos entrevistados não estavam hospedados em um dos três municípios em foco (Gráfico 4), ou seja, Arraial do Cabo, Cabo Frio e Armação dos Búzios. Também se revelou significativa a informação de que cerca de dois terços dos entrevistados em Arraial do Cabo não estavam hospedados no município, como atesta o mesmo Gráfico 4. Para além disso, observa-se, conforme atesta o Gráfico 6, que a maioria dos entrevistados em Arraial do Cabo passa a maior parte do tempo nos outros dois municípios, Armação dos Búzios e Cabo Frio. A posição geográfica de Arraial do Cabo e as atividades de excelência desenvolvidas no turismo local, como pesca submarina e mergulho de apreciação da paisagem submarina, explicam, em grande parte, o fato de a maior parte dos entrevistados não estar hospedada naquele município. Há um intenso afluxo para o município por essas duas razões. Por outro lado, não se despreza o fato de que os municípios de Armação dos Búzios e Cabo Frio possuírem serviços muito mais diversificados do que aqueles presentes em Arraial do Cabo, razão maior para os dois primeiros terem primazia no quesito hospedagem.

Gráficos. Dados colhidos em Armação dos Búzios

\section{1 - Cidade da Região dos Lagos em que está hospedado}

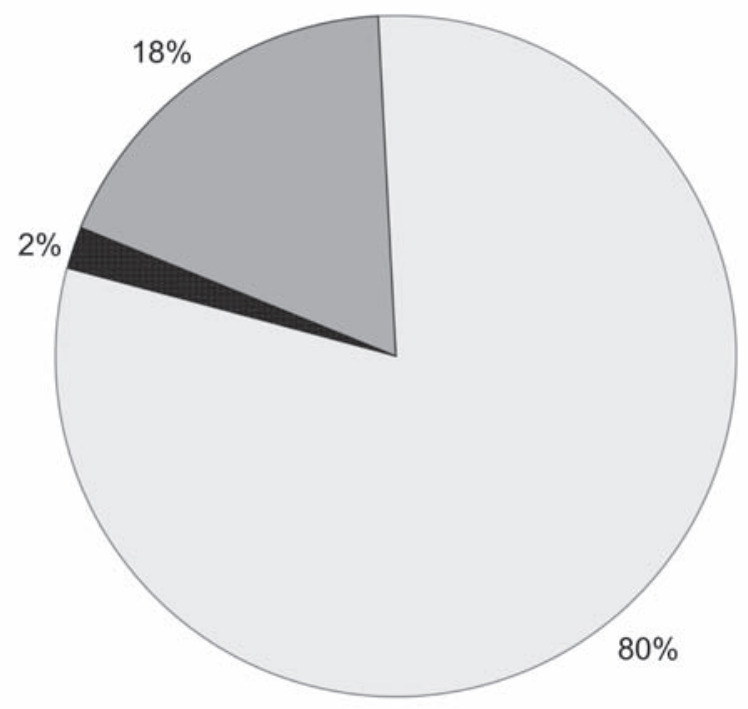

Armação dos Búzios

Cabo Frio

Arraial do Cabo

Produzido por: Thiago Silvestre. Universidade do Estado do Rio de Janeiro Praia de Geribá, Búzios, 29/04/2012 Amostra: 50 entrevistados 


\section{2 - Cidades mais visitadas na Região dos Lagos}

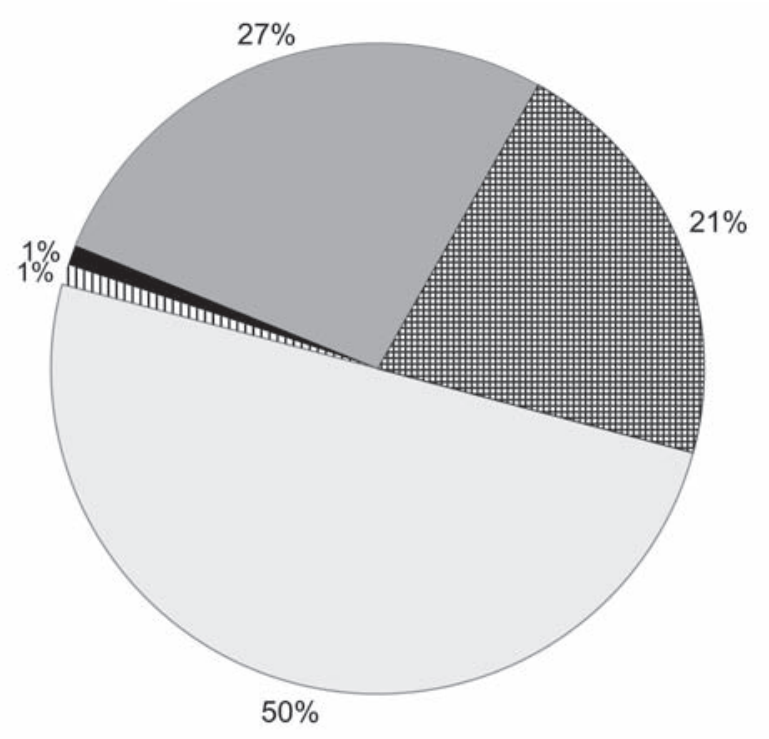

$\square$ Armação dos Búzios

Arraial do Cabo

$\square$ Cabo Frio

- São Pedro D'Aldeia

I Saquarema

Produzido por: Thiago Silvestre. Universidade do Estado do Rio de Janeiro

Praia de Geribá, Búzios, 29/04/2012 Amostra: 50 entrevistados

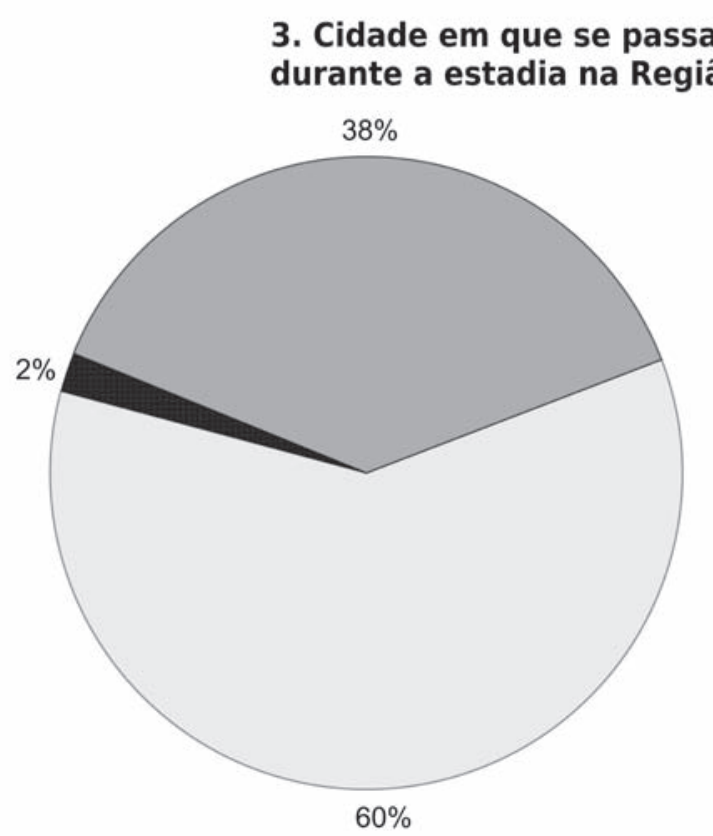

Produzido por: Thiago Silvestre. Universidade do Estado do Rio de Janeiro

Praia de Geribá, Búzios, 29/04/2012 Amostra: 50 entrevistados 
Gráficos. Dados colhidos em Arraial do Cabo

\section{4 - Cidade da Região dos Lagos em que está hospedado}

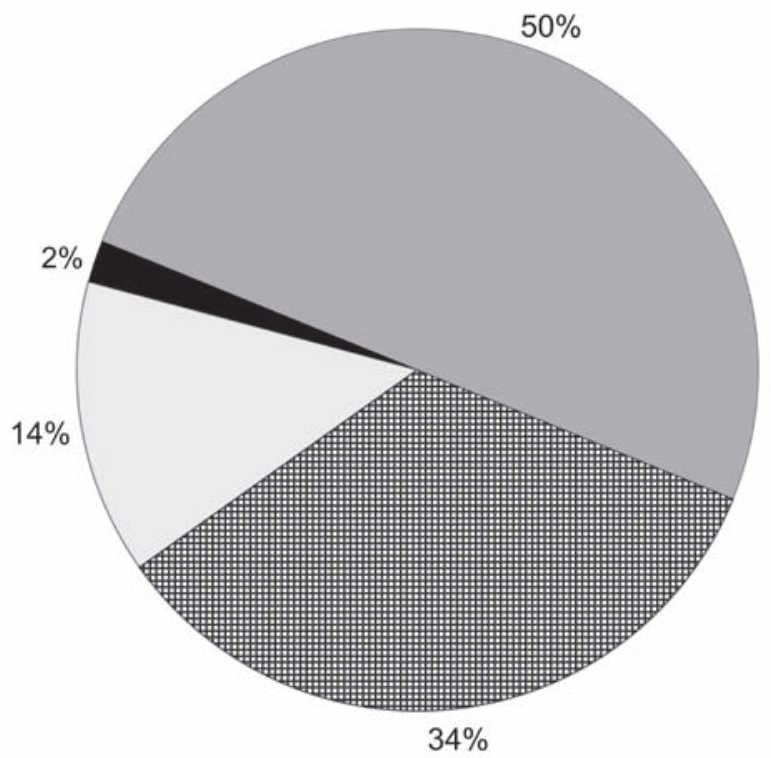

$\square$ Armação dos Búzios

Arraial do Cabo

$\square$ Cabo Frio

- São Pedro D'Aldeia

Produzido por: Thiago Silvestre Universidade do Estado do Rio de Janeiro Prainha, Arraial do Cabo, 07/04/2012 Amostra: 50 entrevistados

\section{5 - Cidades mais visitadas na Região dos Lagos}

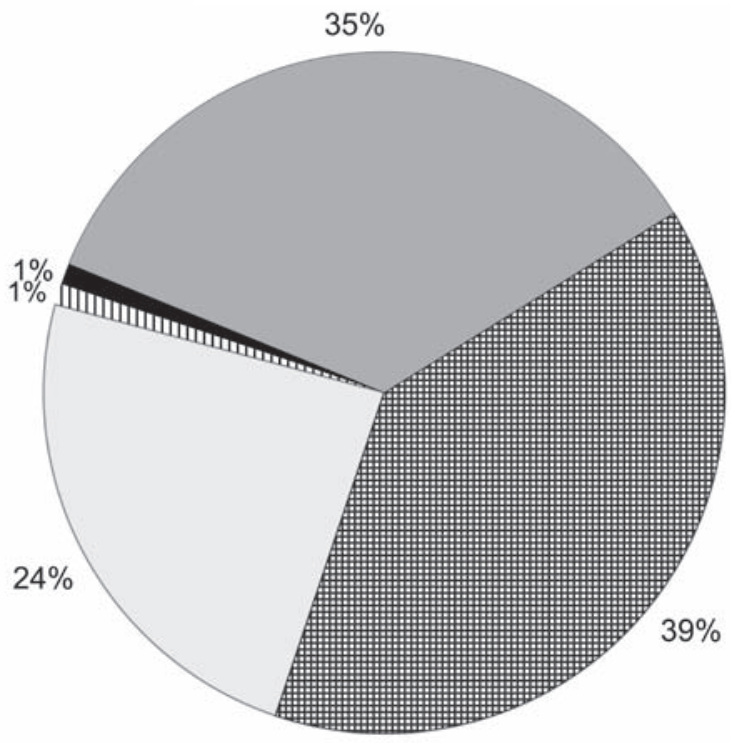

$\square$ Armação dos Búzios

\#\# Arraial do Cabo

$\square$ Cabo Frio

- São Pedro D'Aldeia

II Saquarema

Produzido por: Thiago Silvestre. Universidade do Estado do Rio de Janeiro Prainha, Arraial do Cabo, 07/04/2012 Amostra: 50 entrevistado 
A flutuação turística na região das Baixadas Litorâneas (RJ)

\section{Cidade em que se passa mais tempo durante a estadia na Região dos Lagos}

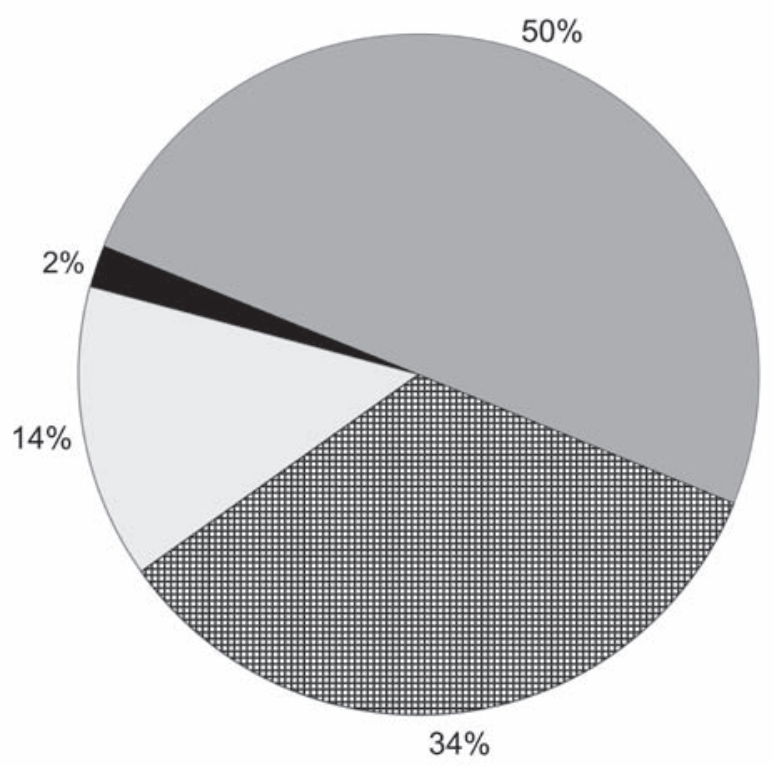

$\square$ Armação dos Búzios

曹 Arraial do Cabo

$\square$ Cabo Frio

São Pedro D'Aldeia

Produzido por: Thiago Silvestre. Universidade do Estado do Rio de Janeiro Prainha, Arraial do Cabo, 07/04/2012 Amostra: 50 entrevistados

Gráficos. Dados colhidos em Cabo Frio

\section{7 - Cidade da Região dos Lagos em que está hospedado}

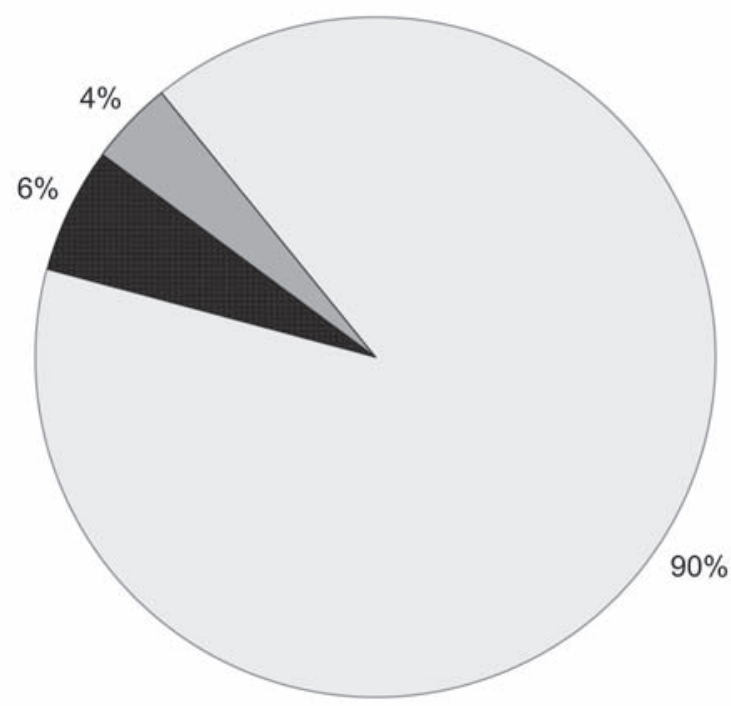

$\square$ Cabo Frio

$\square$ Arraial do Cabo

- Armação dos Búzios

Produzido por: Thiago Silvestre Universidade do Estado do Rio de Janeiro Praia do Forte, Cabo Frio, 06/04/2012 Amostra: 100 entrevistados 


\section{8 - Cidades mais visitadas na Região dos Lagos}

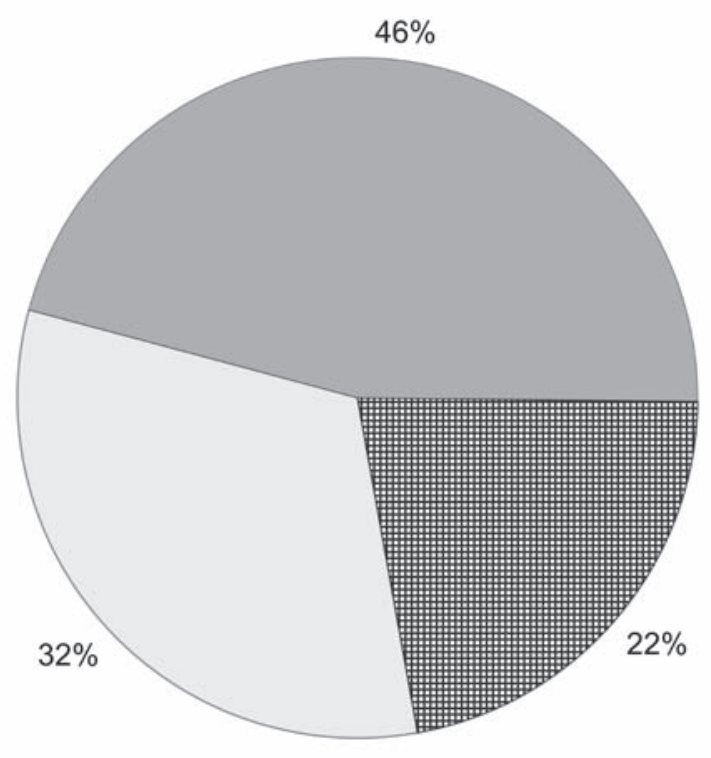

$\square$ Armação dos Búzios

曹 Arraial do Cabo

$\square$ Cabo Frio

Produzido por: Thiago Silvestre. Universidade do Estado do Rio de Janeiro Praia do Forte, Cabo Frio, 06/04/2012

Amostra: 100 entrevistados

9. Cidade em que se passa mais tempo durante a estadia na Região dos Lagos

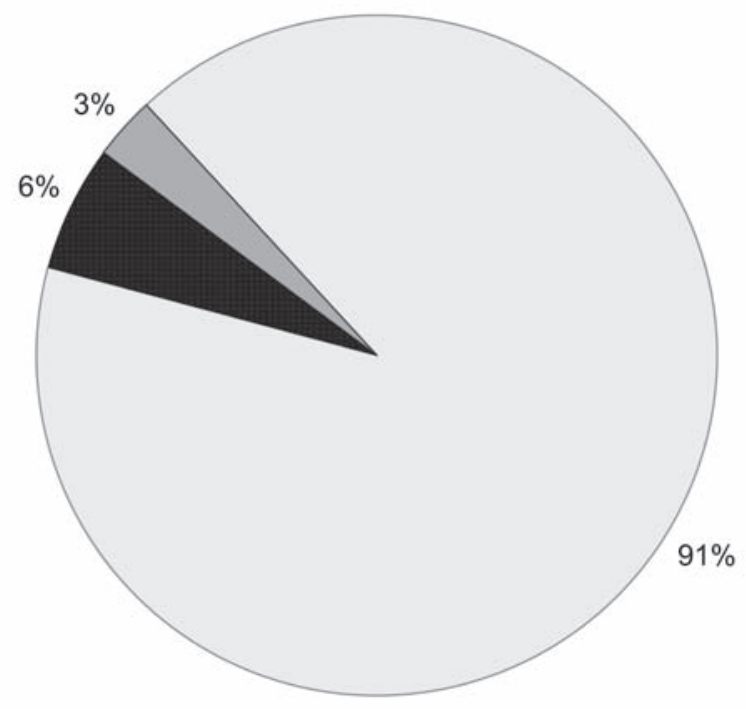

Produzido por: Thiago Silvestre. Universidade do Estado do Rio de Janeiro

Praia do Forte, Cabo Frio, 06/04/2012 Amostra: 100 entrevistados 


\section{A flutuação turística na região das Baixadas Litorâneas (RJ)}

Em Cabo Frio, os entrevistados, em sua grande maioria, estavam hospedados na própria cidade. Nesse município, observou-se, conforme apresentado no Gráfico 7, que raríssimos eram aqueles não hospedados, para além da localidade analisada, fosse em Armação dos Búzios ou em Arraial do Cabo. De acordo com o Gráfico 8, a flutuação-mobilidade identificada diz respeito àquela encontrada em Arraial do Cabo, ou seja, os três centros turísticos se completam em termos de mobilidade, porém os demais dessa região de governo não interagem nesse quesito. Observa-se que os turistas entrevistados em Cabo Frio são aqueles que mais tempo permanecem no município, como apontam os Gráficos 3, 6 e 9.

Em Armação dos Búzios, cerca de três quartos dos entrevistados se encontravam hospedados na própria cidade (Gráfico 1), número tão significativo quanto aquele encontrado em Cabo Frio. Entretanto, quando se considera a mobilidade dentro do conjunto de municípios da região das Baixadas Litorâneas, também em Armação dos Búzios destaca-se a mobilidade interna, que volta a apresentar padrão similar ao dos demais municípios analisados, com ocorrência do fenômeno praticamente limitado a essa trinca de cidades, conforme se constata no Gráfico 2.

É certo que a motivação turística incide, predominantemente, sobre os resultados obtidos. Mas o que leva determinado turista a considerar suas predileções de uso turístico resulta de um conjunto de considerações que passam pelos atributos naturais e histórico-culturais identificados em Ribeiro (2003) e Gomes (2010), pelas análises de Boulón (2002) sobre paisagem, estrutura e superestrutura turística, pela questão da mobilidade proposta por Urry (2000) e pelas motivações turísticas propostas por Shaw e Williams (2004). Corroborando essa ideia e levando em conta todos os turistas entrevistados, raros foram os que não consideraram os municípios de Cabo Frio, Armação dos Búzios e Arraial do Cabo aqueles com as atividades turísticas mais desenvolvidas. De fato, a mobilidade existe, mas apenas na área turística que congrega os três centros turísticos, o que nos leva a verificar que, para além da mobilidade, também existe uma flutuação entre esses municípios, pois a rede viária permite esse tipo de deslocamento e a maior das atrações turísticas é a praia.

\section{Considerações finais}

A análise dos dados coletados à luz da base teórica apresentada no estudo organizado por Gomes (2010) e na obra de Boullón (2002) nos conduz a duas consideraçóes fundamentais: a área turística em foco não concorre com a região de governo das Baixadas Litorâneas, pois é mínima a mobilidade turística que envolve os municípios não destacados; a área turística realmente se concentra nos municípios destacados, pois a mobilidade é imperceptível para além deles.

Os atrativos turísticos presentes tanto em Arraial do Cabo como em Cabo Frio e Armação dos Búzios dimensionam uma qualificação turística para dada porção da região de governo das Baixadas Litorâneas. É certo que os dados demonstram laços por demais significativos entre os três centros turísticos, como também é certo afirmar que ocorre uma interação mínima entre os demais municípios da região de governo. Por outro lado, o avanço nesta pesquisa pressupóe a coleta de dados nos municípios não contemplados nesta primeira análise. Se a escolha preestabelecida dos municípios guarda posicionamento metodológico prévio, também é producente verificar que tipo de mobilidade - se é que realmente existe - ocorre entre os demais municípios da região de governo. 
Acreditamos que algumas condições preexistentes e alguns atributos da paisagem natural condicionaram a maior intensificação do uso turístico nos municípios de Cabo Frio, Arraial do Cabo e Armação dos Búzios. A imaginação analítica permite avaliar que as propostas de ação pública vinculadas aos demais municípios da região devem levar em conta que a maior qualificação das atividades de cunho turístico permitiria maior inter-relação entre eles.

\section{Referências}

BOULLÓN, Roberto C. Planejamento do espaço turístico. Bauru: EDUSC, 2002.

FODNESS, D. "Measuring Tourist Motivation". Annals of Tourism Research: A Social Sciences Journal, 1994.

GOMES, João Carlos (org.). Caderno de turismo do estado do Rio de Janeiro: passaporte para o desenvolvimento do estado. Rio de Janeiro: Fecomércio, 2010.

GUIMARĀES, Vera. "Globalização e mobilidade: as condições de mobilidade contemporânea e as práticas turísticas”. Revista Contemporânea, 18 ed., 2011.

HANNAM, Kevin et al. "Mobilities, immobilities and moorings". Mobilities, Londres, v. 1, n. 1, mar. 2006, pp. 1-22. Disponível em: http://dx.doi.org/10.1080/17450100500489189. Acesso em: 24 maio 2012.

HARVEY, David. Condição pós-moderna. São Paulo: Loyola, 1996.

LASH, Scott e URRY, John. Economies of signs \& space. Londres: Sage Publications, 1994.

MARAFON, Glaucio et al. Geografia do estado do Rio de Janeiro: da compreensão do passado aos desafios do presente. Rio de Janeiro: Gramma, 2012.

PEARCE, Douglas G. e BUTLER, Richard (orgs.). Tourism research: critiques and challenges. Londres: Routledge, 1994.

RIBEIRO, Miguel Angelo. “Turismo no estado do Rio de Janeiro: ensaio de uma tipologia”. GEOgraphia, Niterói, v. 5, n. 10, 2003, pp. 79-91.

RODRIGUES, Adyr B. (org.). Turismo e geografia: reflexões teóricas e enfoques regionais. 2 ed. São Paulo: Hucitec, 1999.

SHAW, Gareth e WILLIAMS, Allan M. Tourism and tourism spaces. 1 ed. Londres: Thousand Oaks/ Nova Déli: Sage Publications, 2004.

URRY, John. O olhar do turista: lazer e viagens nas sociedades contemporâneas. São Paulo: Studio Nobel, Sesc, 1996.

- Sociology beyond societies: mobilities for the Twenty-First Century. 1 ed. Londres: Routledge, 2000 . 